\title{
Conversion of a conventional tailings storage facility to a perimeter discharge central decant configuration using Nalco WaterShed polymer
}

\author{
F Verdoorn SIMEC Mining, Australia \\ K Gibbs Nalco Water Pty Ltd, Australia
}

\begin{abstract}
In 2012, SIMEC Mining commenced a detailed investigation into changing the way the magnetite tailings storage facility (Mag TSF) operates at the South Middleback Ranges (SMR) to increase water recovery and provide a sustainable cost-base for tailings management. Changes were also necessary to support the Magnetite Expansion Project (MEP) that was destined to be commissioned in October 2013. A feasibility study was performed with Golder Associates to understand the technical and commercial influences and provide a capital estimate for several options. The selected option from the study was a redesign of the current dual discharge TSF to a perimeter discharge, central decant (PDCD) design.
\end{abstract}

Application of Nalco WaterShed polymer at the Big Baron Pit (Verdoorn et al. 2018) revealed the technology would greatly assist in the successful conversion of the TSF to a PDCD configuration. Expectation was high that WaterShed polymer treatment would allow greater beach angle control, improved water recovery, and a reduction in surface water pooling across the TSF with water pooling concentrated around the central decant allowing for efficient removal prior to loss via evaporation or seepage.

A conceptual design for the polymer tailings dewatering application was developed in collaboration with Nalco Water and dosing commenced in October 2013. Due to unknown risks associated with dewatering magnetite tailings, the project was split into two stages, namely, phase 1: a proof of concept trial to establish the applicability of Watershed on the magnetite tailings prior to commissioning of MEP; and phase 2: fully operationalise the PDCD configuration.

Golder was engaged to develop a life-of-mine plan for the TSF at SMR that could be safely operated to a planned final height of RL $199 \mathrm{~m}$. Throughout 2013 and 2014, design and construction occurred to convert the Mag TSF to a PDCD facility. A master plan was developed to manage tailings storage for five years from March 2014, referred to as the 'First 5 Year Plan'. This involved six wall raises that would eventually fill the three voids near the western embankment and bring the height of the TSF to RL $172 \mathrm{~m}$.

The civil concept selected was based on an alternatives assessment that presented three options. SIMEC Mining chose the lowest cost approach of filling the voids with WaterShed polymer treated tailings to provide a base for $3 \mathrm{~m}$ wall raises upstream. Strict deposition and water recovery models were followed to ensure sufficient dewatering and the subsequent drying of the tailings layers. There was also extensive test work completed prior to each of the individual embankment raises to ensure that the dewatered tailings had the appropriate density and strength properties to support the raises before commencing with the lifts.

During the first five years of operation, water recovery was around $60 \%$ and the volume utilisation was in line with the deposition model. The high percentage of water recovered enabled the processing plant to reach its new design capability, reduce significant downtime due to water availability and provide the mining operations with sufficient water for dust suppression. The second five-year plan is currently being finalised and progress is consistent with the tailings deposition and the dewatering model.

Keywords: magnetite tailings, perimeter discharged central decant, polymer, first five-year plan, water recovery, deposition and dewatering model 


\section{Introduction}

Magnetite and Hematite Ore are mined from open cut mines on SIMEC Mining's SMR site. The processing plants generate tailings from two different processes. Hematite ore is processed at the ore beneficiation plant (OBP) while magnetite ore is processed at the Concentrator. OBP tailings were previously stored in the OBP TSF while fine tailings from the Concentrator were stored in the Mag TSF.

In addition to fine tailings, both processes also generate a coarse reject. The coarse rejects from the OBP are used in various places around the site (e.g. road sheeting). The coarse tailings from the Concentrator were stockpiled in various locations within the Mag TSF footprint.

The tailings storage facility (TSF) for both the Concentrator and the OBP at the SMR mine site had experienced difficulties with regards to beaching, water-solid separation, consolidation of solids and water recovery prior to 2012. The original plant design limited the performance of the thickener and produced tailings of variable underflow densities that were not appropriate for the Mag TSF design at that stage.

In October 2013, SIMEC Mining implemented the Magnetite Expansion Project (MEP) to increase the production of magnetite concentrate, which increased the production of magnetite tailings by about $50 \%$ ( $\sim 335$ to $\sim 660 \mathrm{~m}^{3} / \mathrm{hr}$ ).

SIMEC Mining intended to decommission the OBP TSF to possibly reprocess the tailings and direct the OBP tailings to the Mag TSF to be dewatered.

With both processing plant tailings streams reporting to one facility, it was crucial to maximise the extracting of water from the main TSF, extraction bores, caisson and dewatering spears around the facilities.

Figure 1 shows an aerial image of the Mag and OBP TSFs and highlights the location of the monitor bores (green), extraction bores (red), pump-out caisson (blue) and dewatering spears (purple).

\section{Operation overview}

The overarching goal of the operation of the Mag TSF under the first five-year master plan was to dewater and store tailings from the Concentrator and OBP for five years from April 2014. To achieve this, the perimeter embankments had to be raised in stages to a uniform level of RL $172 \mathrm{~m}$ and tailings had to be discharged from the full perimeter at this elevation.

Figure 1 shows an aerial image of the Mag TSF in 2013 highlighting the northern, western and southern embankments, northern and southern decants and northern, central and southern voids.

Initially, the embankments varied significantly in elevation and their respective deposition areas varied in size. The northern embankment was between 5 and $10 \mathrm{~m}$ higher than the western embankment, while the deposition areas from the western embankment into the void spaces behind the wingwall buttress were much smaller than the area available behind the northern embankment. A tailings deposition model and sequence were developed to consider the differences in elevation and available deposition area.

The plan was to fill the three voids with WaterShed polymer treated tailings to provide a consolidated base that is strong enough to support a series of six upstream lifts over five years to raise the wall height to RL 172. To facilitate dewatering and consolidation of tailings within these voids, a new temporary decant tower needed to be constructed within each void.

Complementing lifts to the western wall also required raising of the northern and southern walls, which was done in a logical sequence.

Also required was the construction of a new central decant system and central causeway along with a management strategy to transfer decant recovery from the two decant towers located on the western wingwall to the new central tower. 


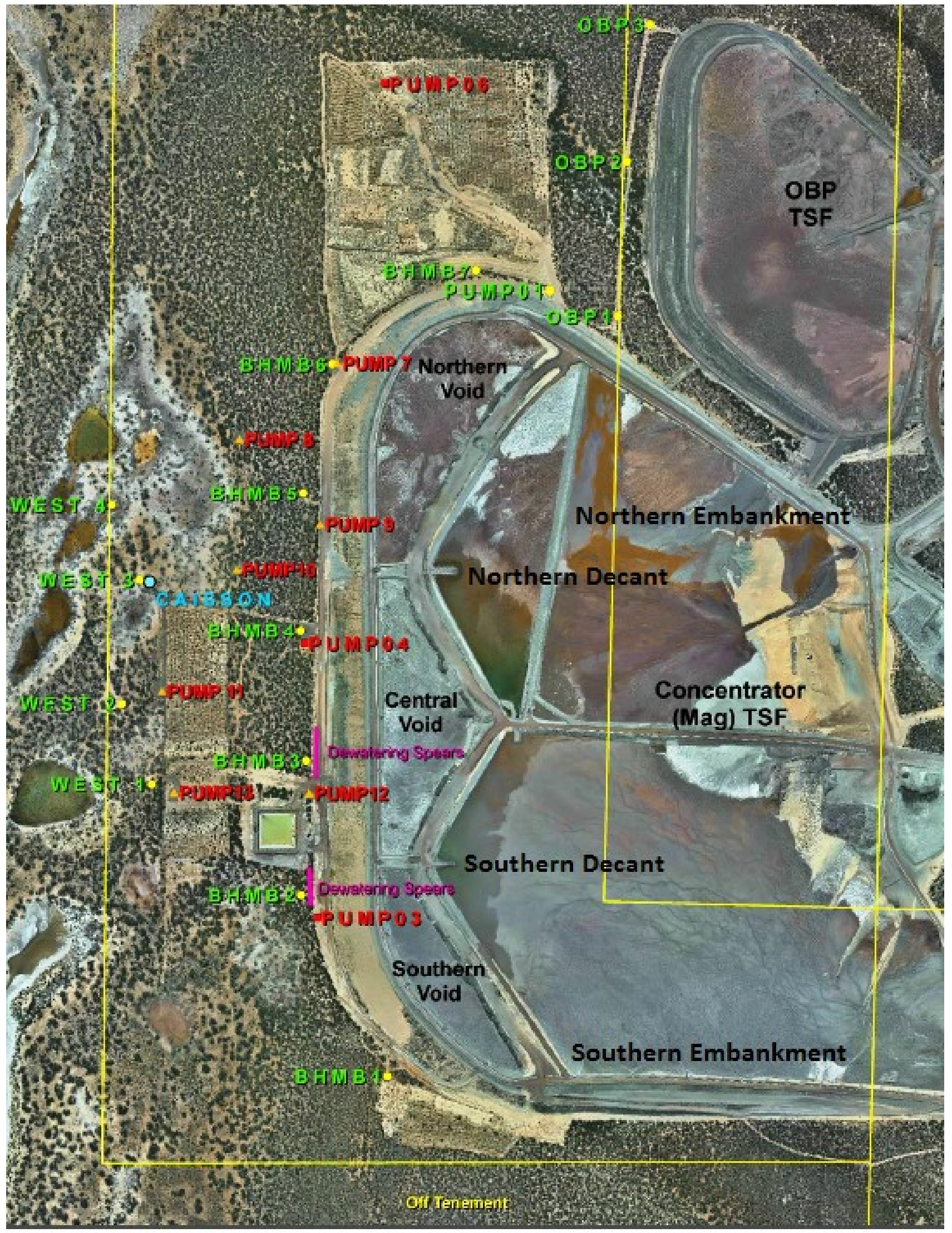

Figure 1 Aerial image of the Mag and OBP TSFs (2013) showing all embankments, voids, decants and the location of the monitor bores (green), extraction bores (red), pump-out caisson (blue) and dewatering spears (purple) 
Spigot design, deposition strategy and TSF operational practices (Golder Associates 2015a) had to be modified to support the overall conversion and efficient operation of the new design.

In general, tailings were deposited in sequence from the northern embankment, western embankment and southern embankment, with preference given to the western embankment to overtop the wingwall as soon as practicable. In this way, the decant pond would be shifted away from the perimeter embankments to the central area of the TSF about two years into the master plan.

Tailings are delivered to the Mag TSF from the OBP and Concentrator as a slurry and deposited from spigot locations at about $50 \mathrm{~m}$ centres. Nalco's WaterShed polymer is transported from the container skid (shown in Figure 2) via a pipeline running adjacent to the tailings lines. Each spigot point comprises a 'mixing chamber' to mix Mag tailings, OBP tailings and polymer as shown in Figure 3. The mixing chamber also acts as protection or shield against high winds that can affect the efficient end-of-pipe mixing of the polymer and tailings. For operational reasons, one spigot is used at a time with regular cycling to deposit tailings in about $300 \mathrm{~mm}$ thick layers and then allow time for drying and consolidation. Supernatant water from the tailings is collected at decant structures within the Mag TSF and returned to the process plant.

The construction of the Mag TSF for the master plan comprises six raises on the western embankment. In addition to the raises on the western embankment, there is a series of associated raises to the central access causeway, northern and southern embankment. However, given the difference in existing elevations, these are not uniform increases in elevation. The embankments will be raised upstream onto the tailings beach. The Mag TSF will therefore be operated to allow for drying and consolidation of the beach to manage risks associated with construction onto tailings.

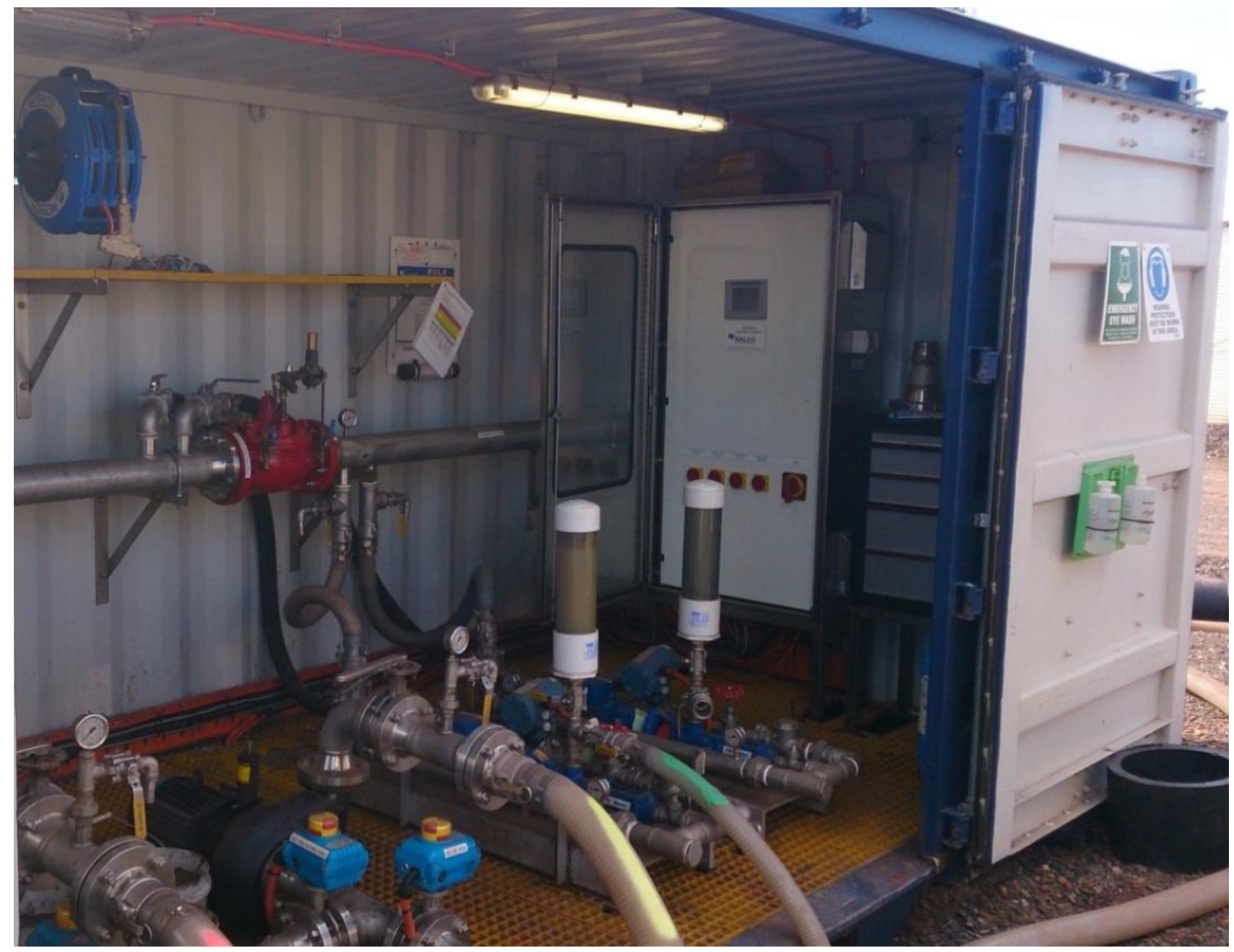

Figure 2 Nalco WaterShed polymer skid container 


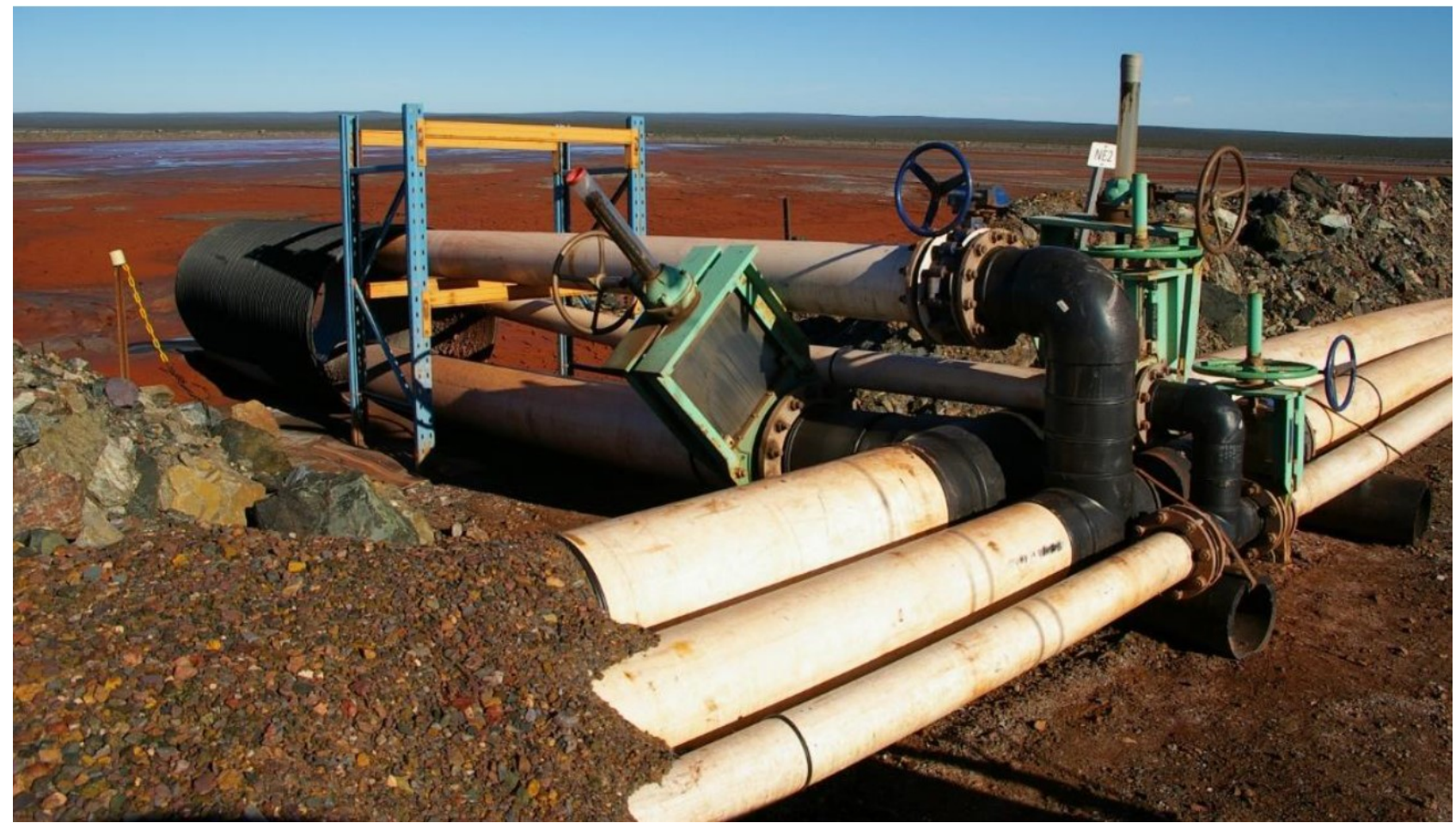

Figure 3 Typical spigot setup: Mag tailings (400 mm high-density polyethylene (HDPE)), OBP tailings (160 mm HDPE), polymer-dilution water (280 mm HDPE) and mixing chamber

\subsection{Tailings management properties}

The design of the master plan for the Mag TSF has an underlying 'basis of design'. Some of the parameter values used in the design require ongoing monitoring.

The Mag tailings properties considered in the design and their threshold limits are outlined in Table 1 . The design prepared by Golder (Golder Associates 2014) is based on a sample of tailings tested in April 2014. The stability of the Mag TSF, the air-drying values of the tailings, and the design of the tailings delivery system are based on the test results of this sample.

Table 1 Tailings management properties and acceptable limits for design compliance

\begin{tabular}{lll}
\hline Parameter & Design value & Acceptable limit/range \\
\hline Liquid limit & $34 \%$ & $\leq 45 \%$ \\
Plasticity index & $8 \%$ & $\leq 13 \%$ \\
Percentage passing $75 \mu \mathrm{m}$ & $90 \%$ & $\geq 80 \%$ \\
$80 \%$ passing particle size, $\mathrm{P}_{80}$ & $35-45 \mu \mathrm{m}$ & $\leq 65 \mu \mathrm{m}$ \\
Average particle size, $\mathrm{D}_{50}$ & $10-20 \mu \mathrm{m}$ & $<40 \mu \mathrm{m}$ \\
Specific gravity of solids & $2.95-3.4$ & $2.95-3.6$ \\
Geotechnical moisture content & $25 \%$ (target value) & $\leq 30 \%$ \\
Dry density & $1.6 \mathrm{t} / \mathrm{m}^{3}$ & $>1.5 \mathrm{t} / \mathrm{m}^{3}$ \\
\hline
\end{tabular}




\subsection{Tailings management objectives}

There are three key tailings management objectives for operation of the Mag TSF namely:

\subsubsection{Dry density/moisture content of the tailings}

The dry density and moisture content of the tailings are critical aspects of the design, specifically as they may preclude raising upstream on the tailings without significant ground improvement, with cost and schedule impacts. Furthermore, if the tailings are stored at an overall lower density and the schedule is affected, additional embankment raises may be required to store the design tonnage of tailings. The key to achieving drying objectives is placing the tailings in thin layers to allow drying and thus increase density and strength. The optimum layer thickness for drying is between 200 and $300 \mathrm{~mm}$. For tailings placed in thicker layers, the lower portion of the layer is likely to remain at a higher moisture content and have a lower dry density and shear strength.

\subsubsection{Beach slope of the tailings}

Beyond end-of-pipe polymer addition at the Mag TSF has been in use since September 2013. One of the key aspects of polymer addition to tailings is that it increases the beach slope near the deposition point. A beach slope of up to $3.7 \%$ has been measured for tailings deposited with polymer compared to a $1 \%$ slope without polymer. The design according to the master plan for the Mag TSF includes a range of beach slopes up to $3.7 \%$ close to the deposition point and reducing to about $1 \%$ over the first $100 \mathrm{~m}$ from the deposition point. The beach slope will be monitored with compliance to the design.

\subsubsection{Clarity of return water from the Mag TSF}

The use of polymer has the effect of settling solids in the supernatant water, thereby improving the clarity of the water decanted from the Mag TSF. Removal of water from the Mag TSF is a key goal to manage the risks associated with seepage, so the use of polymer and the volume of water being returned to the processing plants is a key aspect to monitor and manage during operations design.

\section{Step-by-step plan for conversion to PDCD}

The Mag TSF was progressively converted to a perimeter discharge facility, with a centrally located supernatant decant system. Tailings distribution was going to be from the perimeter embankments and a new pump-out decant was to be constructed near the centre of the TSF. To store the target (life-of-mine) tailings volume, the Mag TSF would have to be raised to a maximum elevation of RL $199 \mathrm{~m}$, or about $65 \mathrm{~m}$ above the existing ground level. The pond will progressively move away from the embankments and towards the centre of the TSF, over the low permeability tailings, where it will be maintained for the remaining life of the facility, as shown in Figure 4.
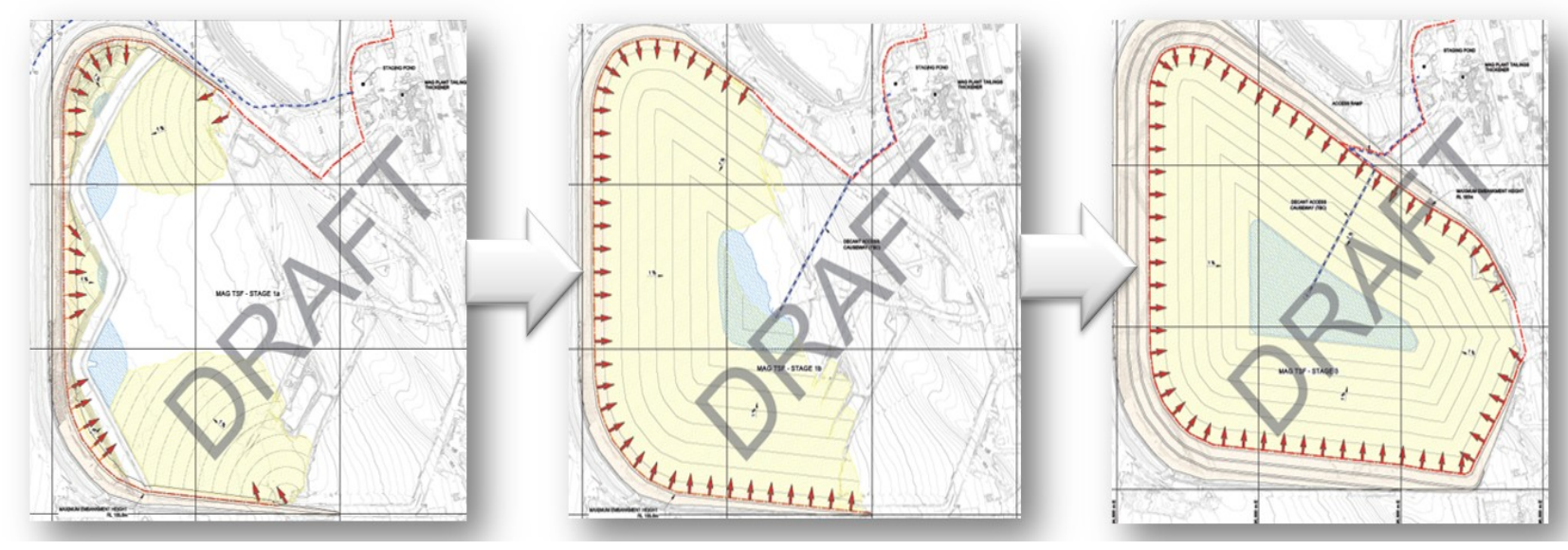

Figure 4 Progressive conversion to a PDCD configuration 


\subsection{Phases 1 to 6 of the conversion}

Between November 2013 and February 2014, Golder began design and construction works at the Mag TSF to convert the facility to a perimeter discharge central decant facility. The construction works were broken into six phases and described as follows:

1. Dewatering trial on the southern embankment.

2. Northern embankment raise.

3. Northern void pump-out decant.

4. Central void pump-out decant.

5. Southern void pump-out decant.

6. Southern embankment raise.

\subsection{Phase 7 of the conversion: the master plan}

The intention of the master plan design was to manage tailings storage at the Mag TSF for five years from March 2014. The master plan design followed the general progression of the Mag TSF developed to support a change to SIMEC Mining's PEPR and raises the embankments to RL $172 \mathrm{~m}$ in six stages (Raises 1 to 6) to cover the five-year period.

The aim of the design was to have the perimeter embankments at the same elevation and the decant pond located near the centre of the Mag TSF. This will enable the deposition of tailings from the entire perimeter and keep the pond remote from the wingwall or perimeter embankments and overlying low permeability tailings.

The construction sequence progressed counter clockwise, that is, raises to the northern embankment and then western embankment with deposition of tailings following behind each construction stage. The design was divided into six approximately $3 \mathrm{~m}$ raises on the western embankment, with each raise including associated raises to the central access causeway and northern and southern embankments. The embankment raises are not uniform increases in elevation due to the variable elevation of the existing embankments. The design allows for tailings deposition to cycle between each of the embankments to allow time for construction. The cycling of tailings deposition around the TSF will allow for increased drying time with a resulting increase in strength and stored density.

Supernatant water was initially being managed from the five existing decants (two gravity decants in the main impoundment area, and three pump-out decants in the wingwall voids), supplemented by a new series of pump-out decants placed centrally in the main TSF area. The plan was to decommission the existing gravity decants as their respective supernatant ponds move towards the new decant. The void decants will initially be raised, and subsequently replaced, by new decants on the wingwall buttress as the tailings fill up the voids. Once the wingwall has been overtopped, additional decants will be constructed in the main TSF to follow the supernatant pond as it moves to the east.

\section{$4 \quad$ WaterShed polymer role in conversion to PDCD}

WaterShed polymer was previously used by SIMEC for treatment of OBP tailings in the Big Baron Pit over several years, resulting in tailings consolidation, pit life extension and excellent water recovery (Verdoorn et al. 2018). WaterShed was identified as a technology that had the potential to significantly assist with the transition of the magnetite TSF to a PDCD configuration.

Lab work had confirmed that the polymer treatment would be just as successful on treatment of magnetite tailings and a combination of hematite and magnetite tailings.

Phase 1 of the conversion was a trial on the southern embankment using five deposition spigots to confirm that the WaterShed polymer was dewatering successfully, and a desired beach was forming. This was then followed by the full-scale installation of the required spigots to facilitate filling of the voids and the TSF 
transition to a PDCD configuration. This trial treated the original magnetite tailings volume combined with the hematite tailings and was used to proof the concept to the regulators before approving the PEPR. Trial results confirmed WaterShed technology would perform to expectation.

Figure 5 shows initial solids consolidation and water shedding across the tailings. The beach formation extended several hundred metres from the deposition point and the released bleed water would flow directly and rapidly to the decant tower before it would be partially lost to evaporation or seepage. The beach angle could be controlled by varying both the WaterShed polymer dose rate and dilution water volume.
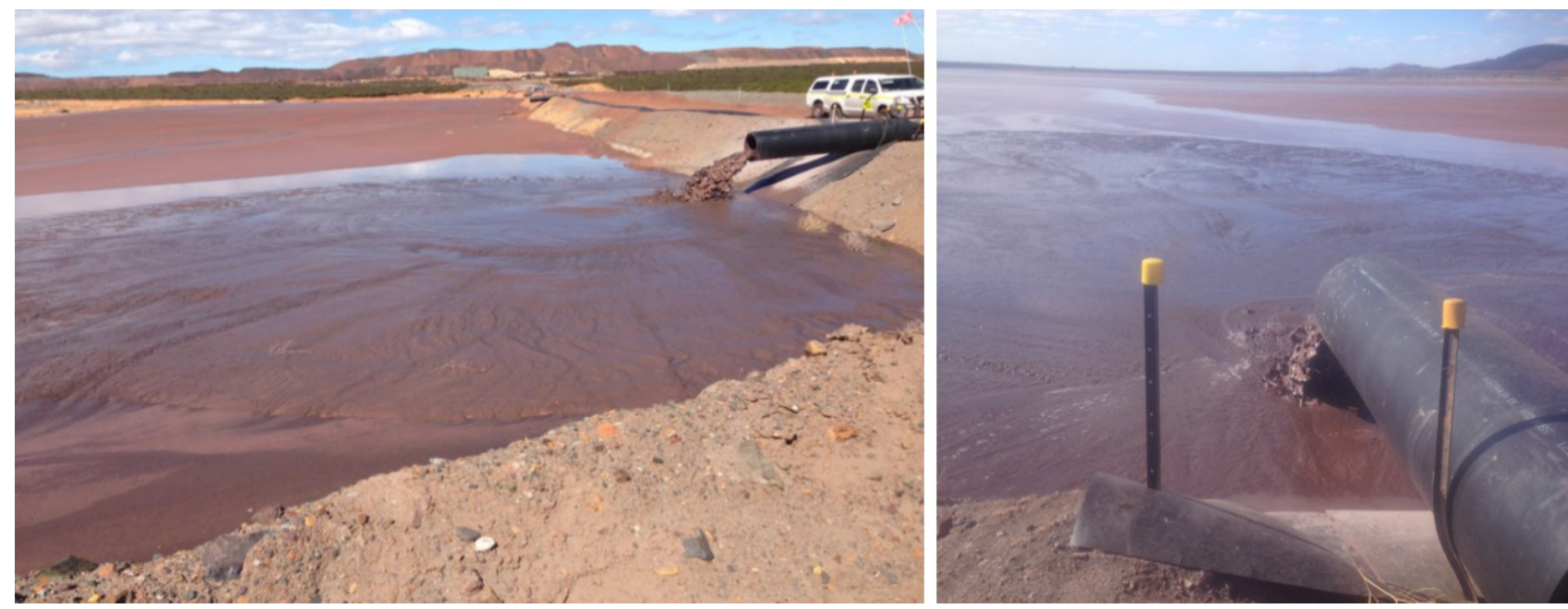

Figure 5 Initial solids consolidation and water release during the initial trial (phase 1)

After the trial, the spigot design was finalised and installation proceeded with 48 spigots installed at $50 \mathrm{~m}$ intervals along the northern, western and southern embankments.

While the void decants, pipework and spigots were under construction. Tailings treatment moved from the trial infrastructure on the southern embankment to the new infrastructure on the northern embankment to establish well defined beaches that were positioned in a way that facilitated flow of decant water towards the decant towers.

WaterShed polymer application strategy used for filling the three voids needed to be different from that used for discharging treated tailings into the main TSF due to the fact that the decants were very close (about $50 \mathrm{~m}$ ) to the outer wall deposition points. Higher dosing rates and less dilution water was needed to create a steeper beach to keep the released water away from the outer walls and the dewatered solids away from the decant filter rock.

\subsection{The voids: WaterShed treatment}

The western voids, before tailings deposition, were about $30 \mathrm{~m}$ deep and an additional lined channel from the mixing chamber to the base of the voids had to be designed using HDPE pipe and/or conveyer belt. This design minimised the shearing of the polymer and treated tailings (which would destroy the flocculated structure, integrity and strength) as well as protecting the western perimeter wall from eroding and scouring.

Given the depth of the voids and the relatively short distance to the newly constructed decant towers within the voids, it was necessary to use a dosing strategy that allowed the establishment of a steep beach angle to facilitate faster dewatering and transportation of bleed water to the towers for immediate removal. One spigot was operated at any one time to maintain mixing dynamics and to facilitate consolidation and strength development within the shortest possible time frame. Treatment was also staggered between the three voids and the individual spigots to allow draining and drying prior to subsequent layering of further solids. The consolidated base was raised by subsequent layering, draining and drying of the deposited material. 
During the filling of the voids and before each wall raise, testing of the deposited solids was carried out by Golder Associates (Golder Associates 2017) to confirm density and strength of the dewatered tailings to support the six planned $3 \mathrm{~m}$ lifts in an upstream construction configuration.

\section{$5 \quad$ Tailings testing and results}

\subsection{Objective}

The objectives of the investigation and analysis were two-fold:

- The objective of the cone penetrometer testing (CPT) investigation (shown in Table 2) was to investigate the in situ tailings in the Mag TSF voids to obtain greater confidence in key stabilityrelated parameters of the tailings, specifically the undrained shear strength and the post-liquefied strength ratio. The results of the CPT investigation will inform early decisions about future planning for the Mag TSF to manage the risks of instability.

- The objective of the hand shear vane testing (shown in Table 2) was to assess the undrained shear strength of the tailings within about $1 \mathrm{~m}$ of the tailings beach surface. Test results were to provide SIMEC Mining with the confidence that the next episode of construction on the embankments could safely proceed.

Vibrating wire piezometers measure pore water pressure to determine slope stability in the consolidated tailings and were installed beneath Raise 1 and Raise 4.

Table 2 Different tests and monitoring systems used during and before embankment raises

Cone penetrometer testing (CPT)
- Before Raise 1 and Raise 4
- Checks strength of tailings at depth
pressures
Shear vane testing
- Before each embankment raise
- Tests upper layers
- Checks immediate strength of tailings
- Target value of 20 kPa (min)
Vibrating wire piezometer
- Measures pore water pressure to
determine slope stability
Installed beneath Raise 1 and Raise 4




\subsection{Geotechnical investigation}

\subsubsection{CPT investigation}

CPT testing was done in regular intervals during the first five years of embankment raises. The probing was carried out by a track-mounted rig, as shown in Figure 6.

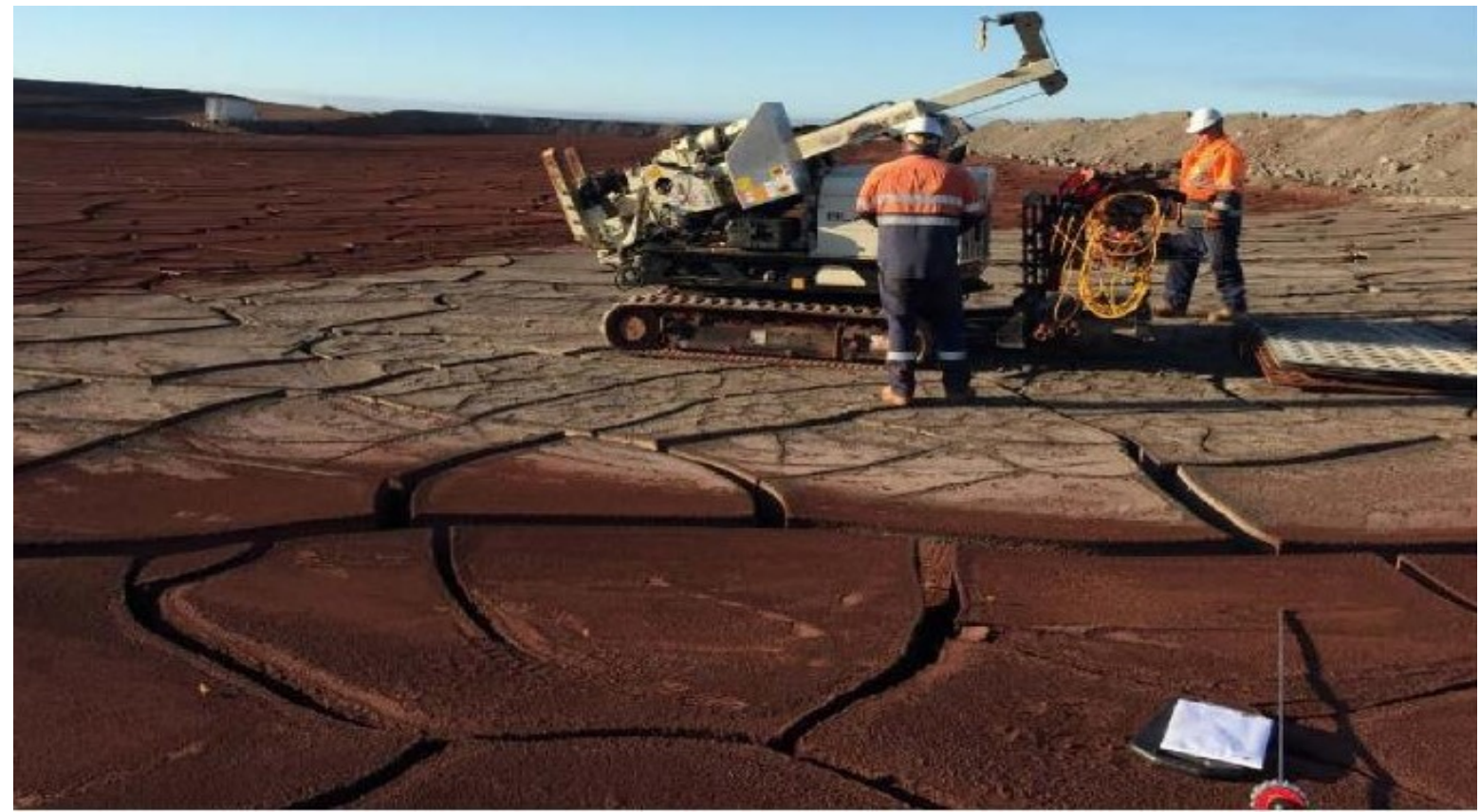

Figure 6 CPT testing in the northern void with track-mounted rig

The testing in 2015 (Golder Associates 2015b) comprised two probe locations in the northern void, three probe locations in the central void and one in the southern void of the Mag TSF, as shown in Figure 7. Test locations were recorded using a hand-held GPS and are shown as red dots in Figure 7. The CPTs ranged in depth from 10.85 to $13.00 \mathrm{~m}$ in the northern void, and 5.69 to $8.42 \mathrm{~m}$ in the central void. The stability assessment indicated that the minimum factors of safety are met for all scenarios considered and that all the embankments raises could safely proceed as planned.

\subsubsection{Hand shear vane testing}

The locations of the hand shear vane tests are shown in Figure 7 (green dots) and a summary of the key results are as follows:

- Testing along the northern embankment indicated a minimum undrained shear strength at the surface of about $87 \mathrm{kPa}$, and a maximum reading of $277 \mathrm{kPa}$.

- Along the northern groyne and central causeway, the minimum reading was $25 \mathrm{kPa}$, up to maximum readings of $134 \mathrm{kPa}$ and $99 \mathrm{kPa}$, respectively.

- In the northern and central voids, the minimum readings were $40 \mathrm{kPa}$ and $96 \mathrm{kPa}$, up to maximum readings of $290 \mathrm{kPa}$ and $309 \mathrm{kPa}$, respectively.

- As expected, the strength of the tailings was generally lower towards decant locations, especially along the northern groyne as the test locations advanced towards the central decant.

- The minimum undrained shear strength required for each of the raises was $20 \mathrm{kPa}$. The results of the shear vane testing comply with the specification and therefore the construction did commence successfully. 


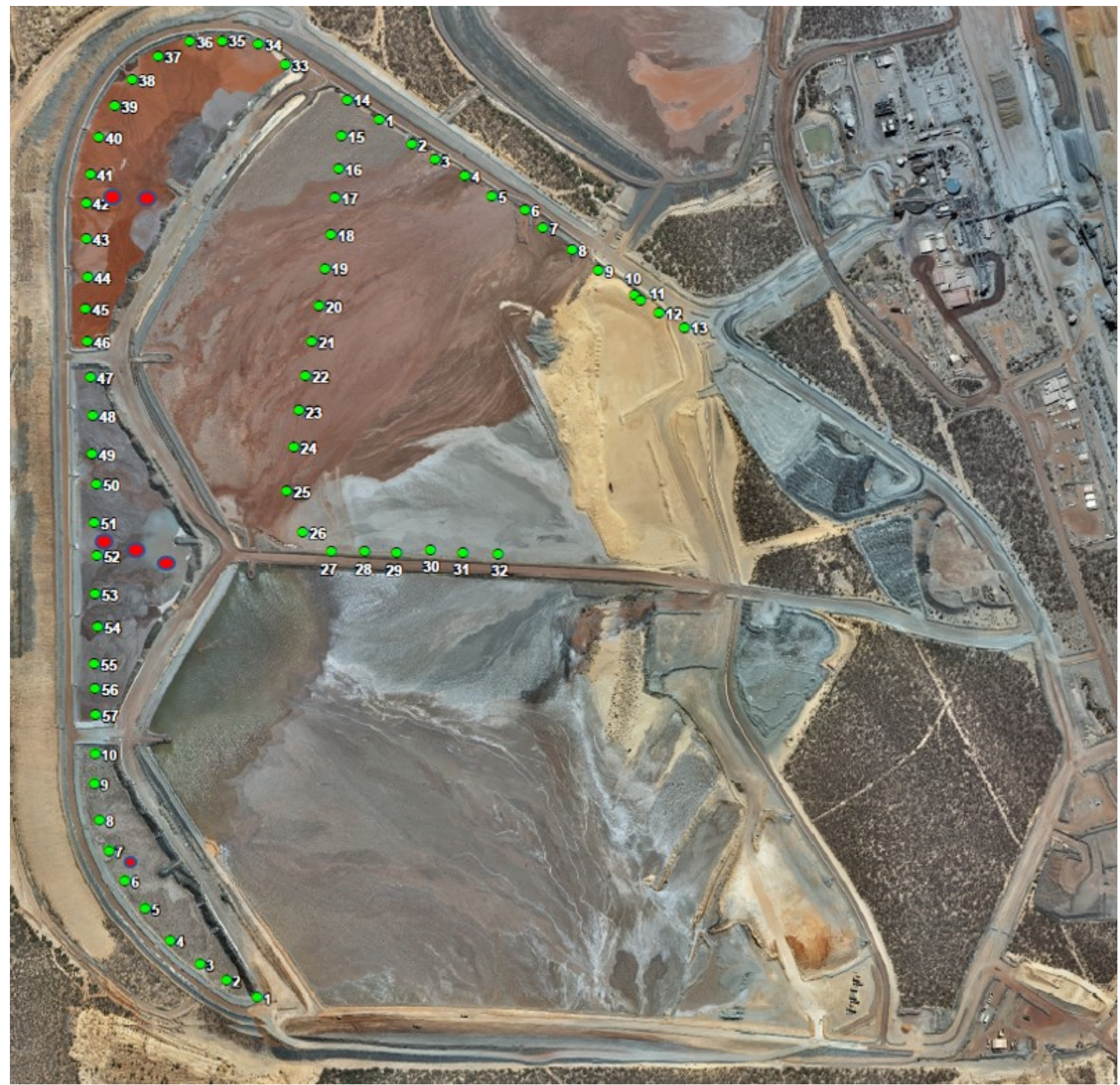

Figure 7 Cone penetrometer test (red dots) and shear vane test (green dots) locations

\section{Progress over the first five years}

The sequence of embankment raises and conversion to PDCD over the first five years is shown in Figure 8. The black is the embankment raise, grey is the tailing deposition, and blue is the water recovery (via decants). 


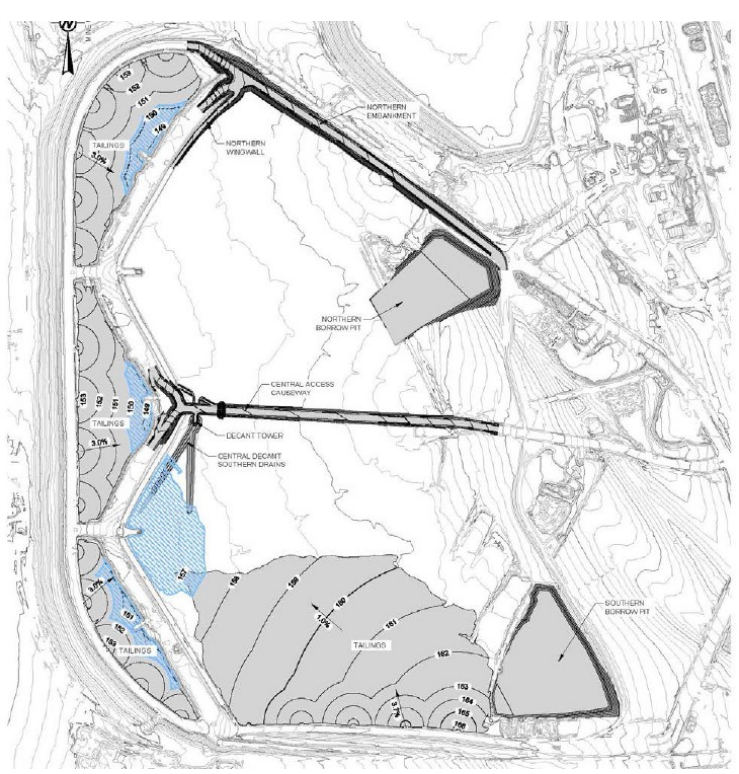

November 2014

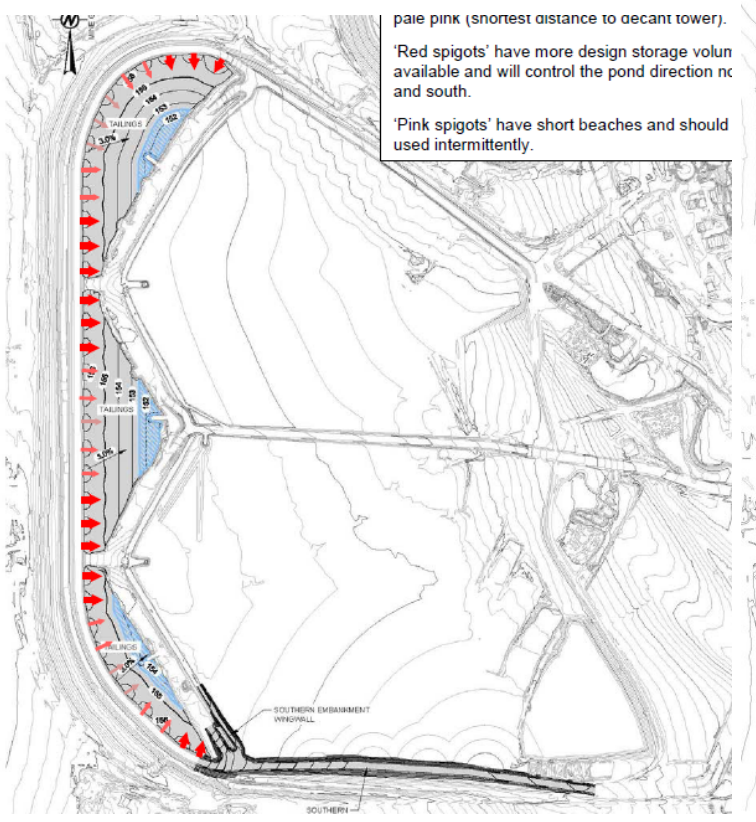

May 2015

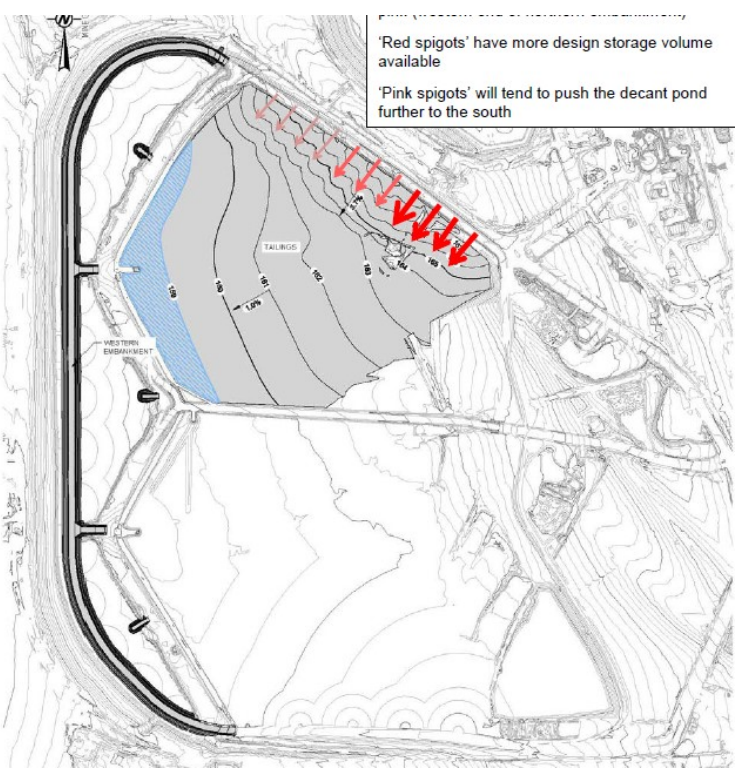

March 2015

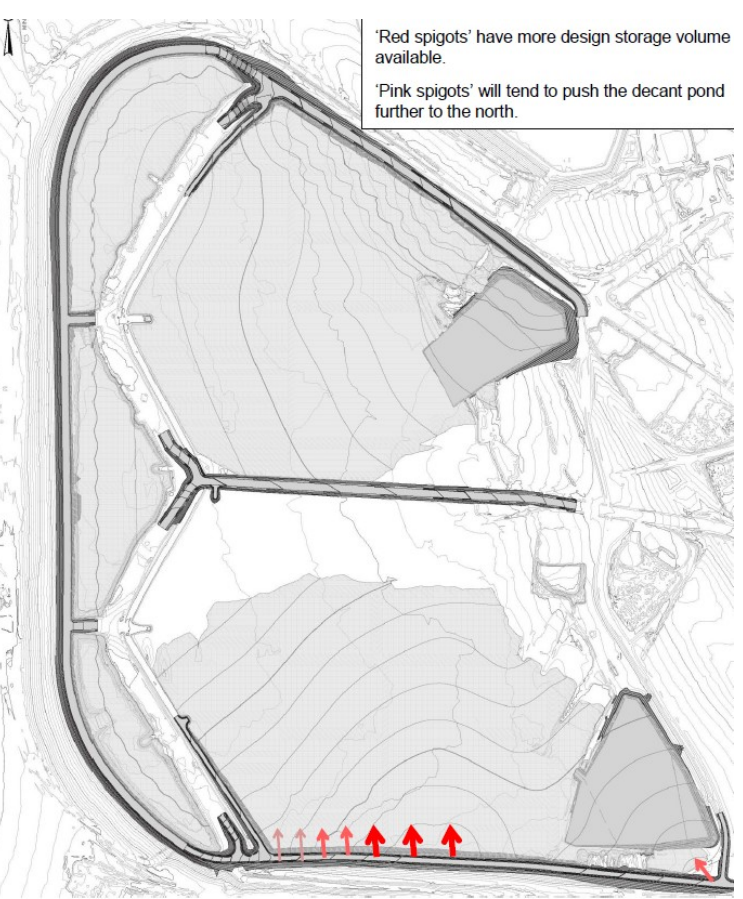

August 2015 


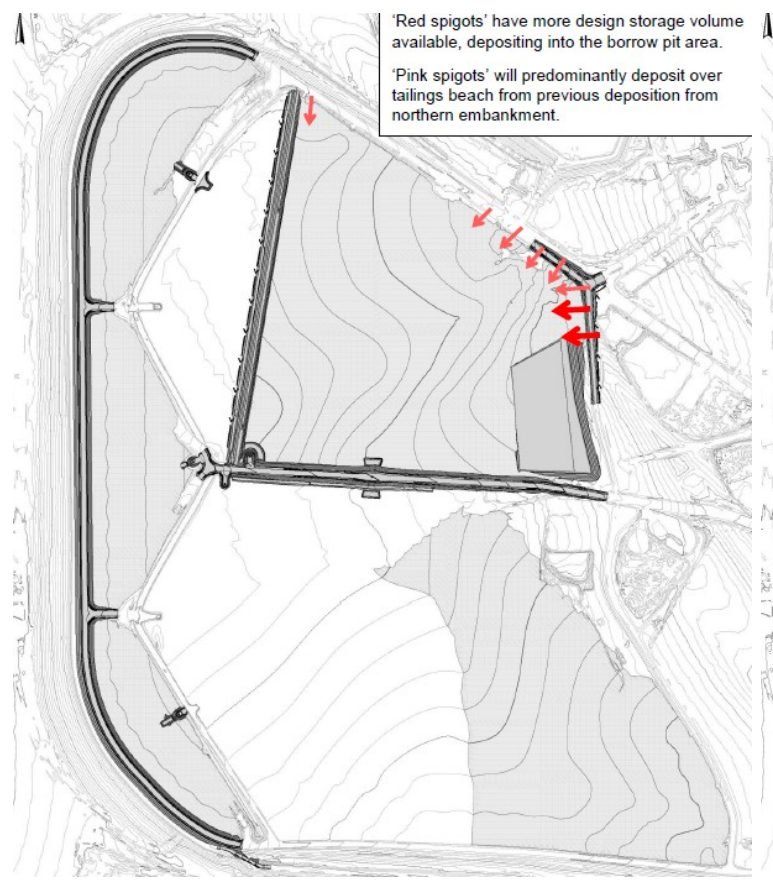

November 2015

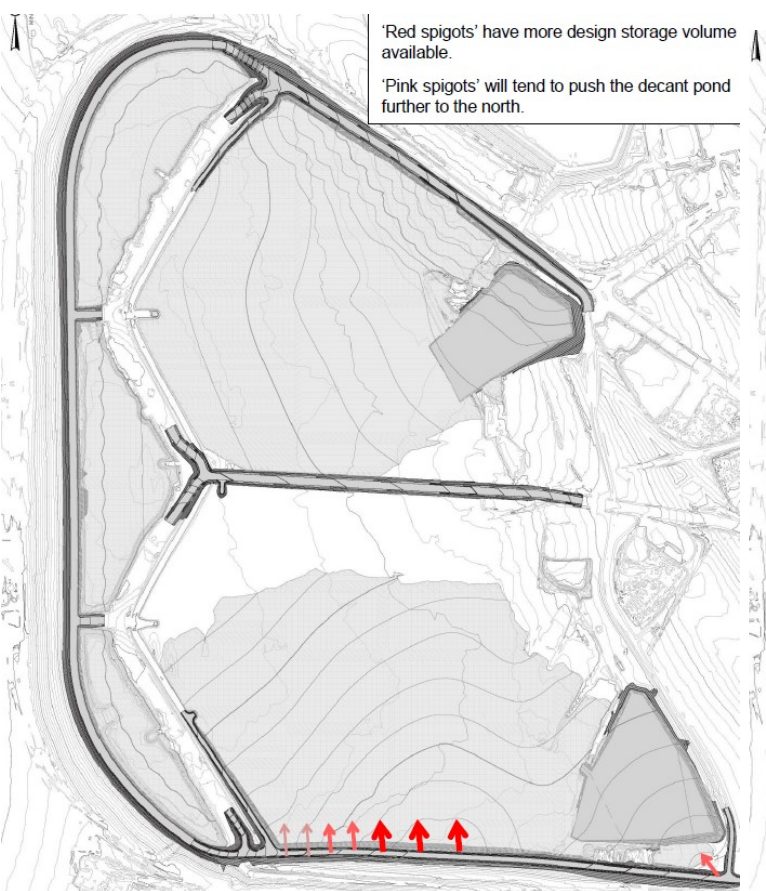

March 2016

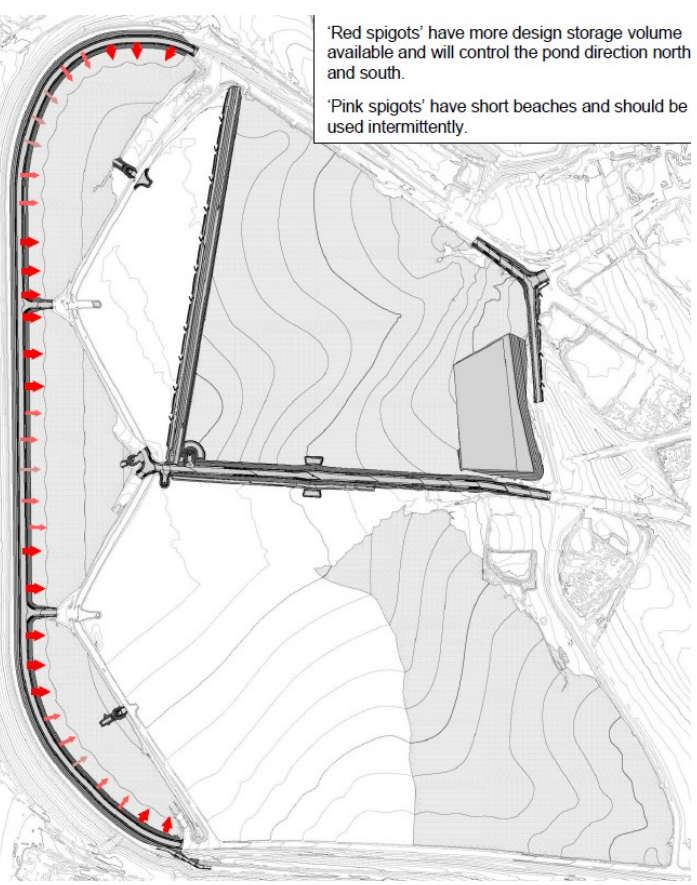

December 2015

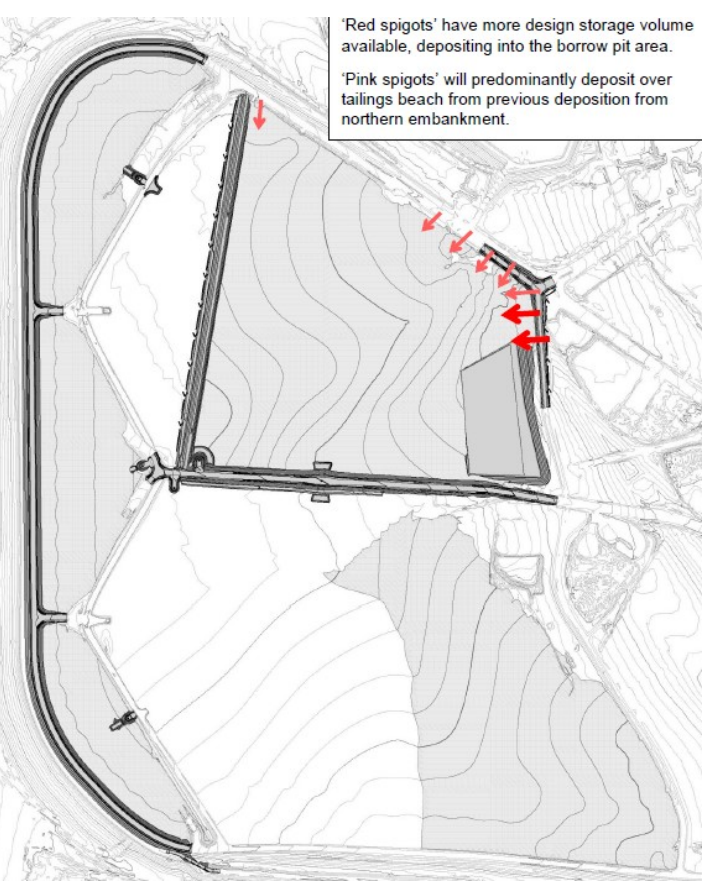

July 2016 


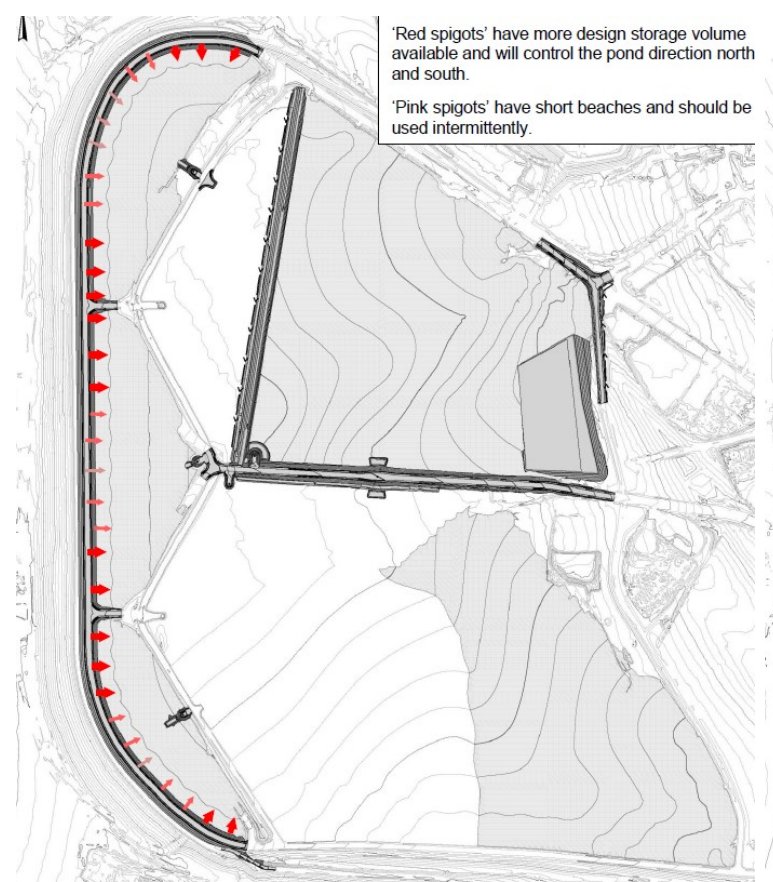

November 2016

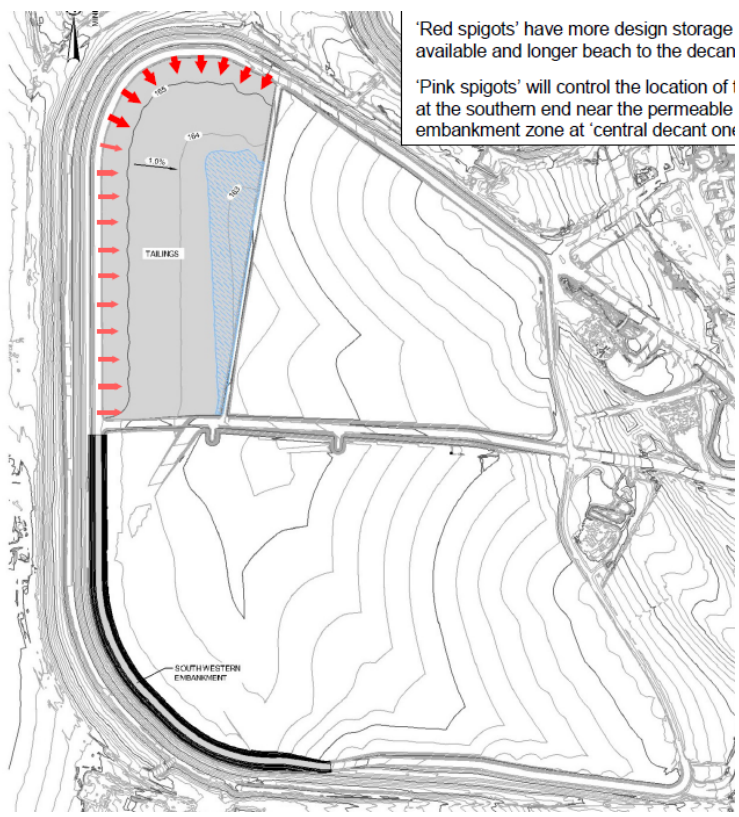

December 2017

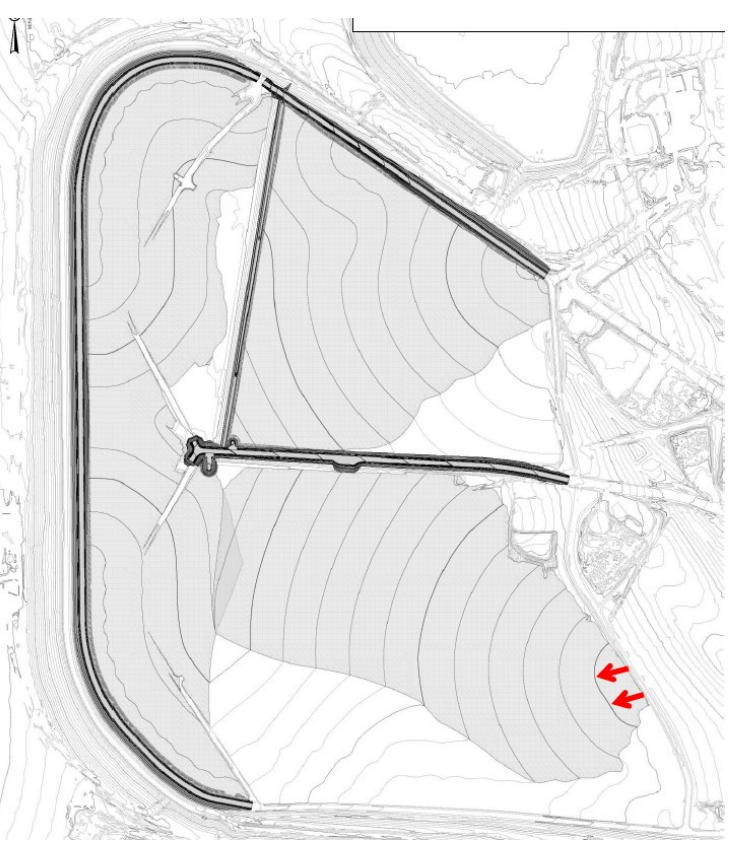

June 2017

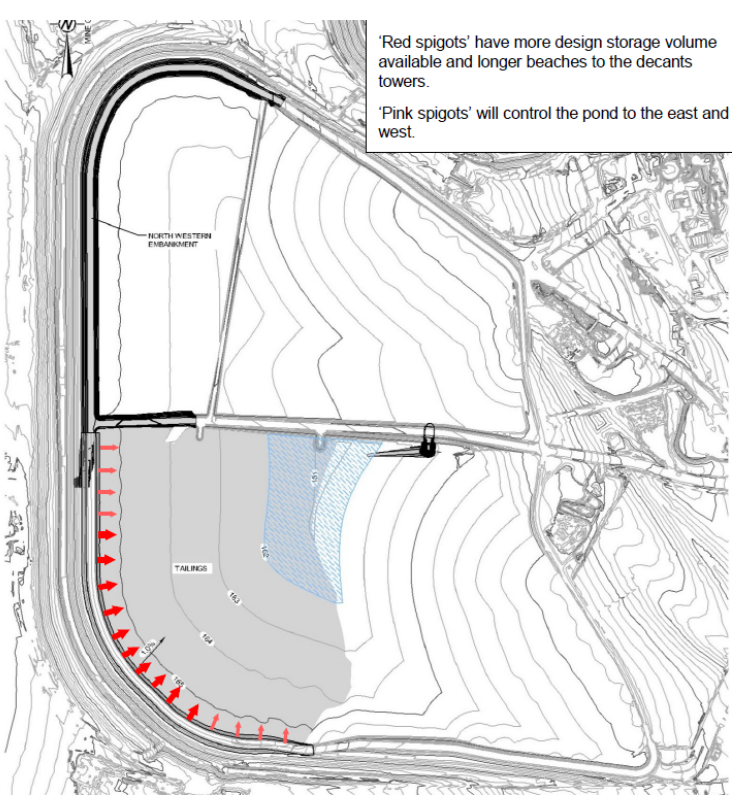

July 2018

Figure 8 Sequence of embankment raises and conversion to PDCD over the first five years

The three voids at the western embankment that were successfully filled with dewatered tailings as well as the recovered water pooling around the central decant (away from perimeter walls) is shown in Figure 9. It should be noted that four successful $3 \mathrm{~m}$ upstream embankment raises have been completed. 


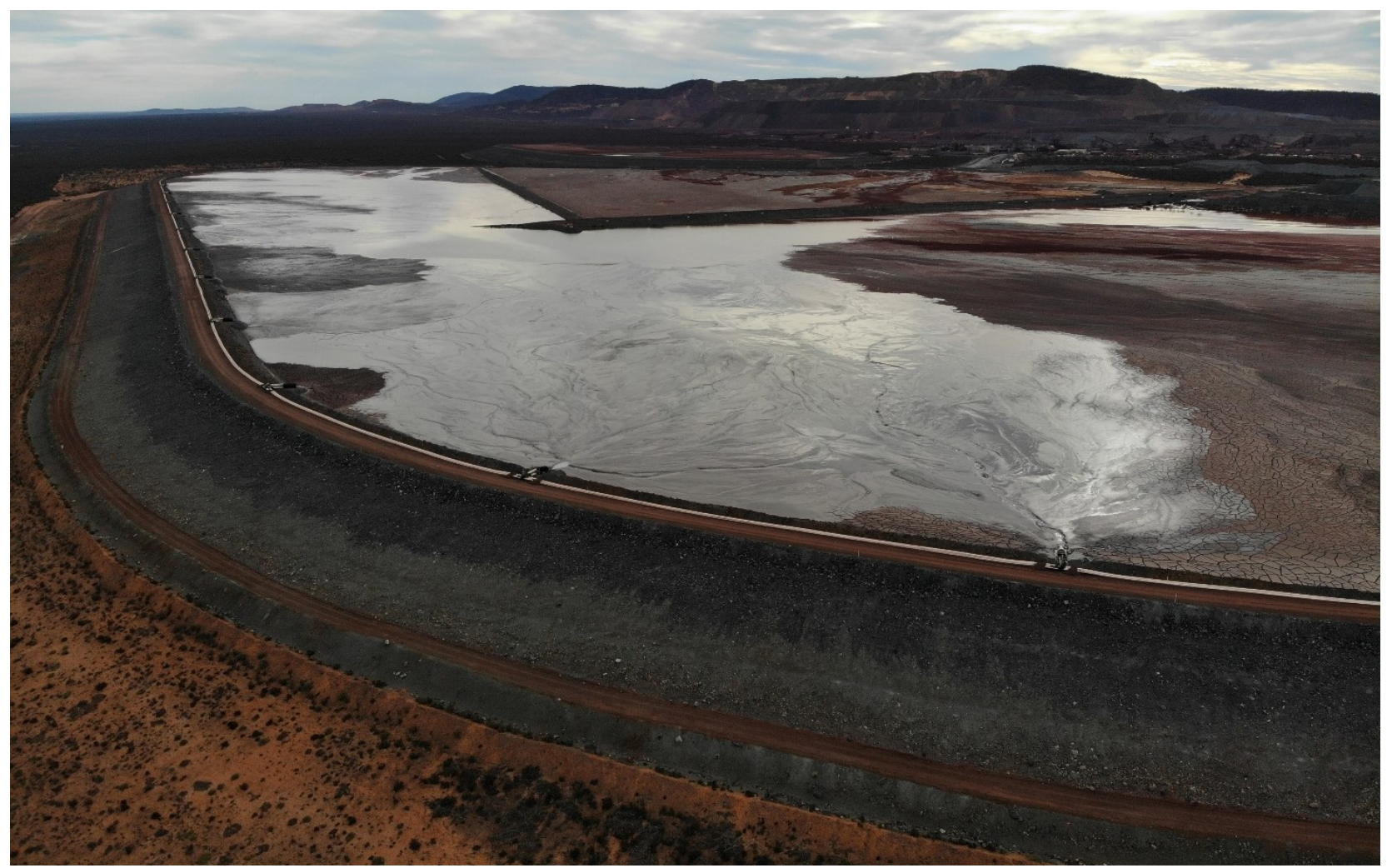

Figure 9 Western embankment June 2017. Note: Voids filled and wingwall overtopped

\section{$7 \quad$ Path forward}

At completion of the First 5 Year Plan around June 2019, the Mag TSF will be a true PDCD tailings storage facility. The western embankment will have risen to RL $172 \mathrm{~m}$ and be level with the intermediate eastern embankment (Figure 10(a)).

The second five-year plan will see the outer embankments raised to encompass the full perimeter of the Mag TSF (Figure 10(b)). The embankments will reach about RL $184 \mathrm{~m}$, level with the existing ground on the far eastern edge. Operation will be greatly simplified with deposition, drying and construction occurring on alternate halves of the TSF. Each raise is effectively completed in two stages, for example, Raise 7 North, Raise 7 South. The rate of rise will be the lowest since the beginning of the master plan, due to filling of the voids. This will provide some flexibility in the frequency and height of wall raises; an optimal frequency will balance mobilisation, construction and demobilisation costs with the cost of additional fill material.

The next five-year plan will be a general description of planned tailings deposition and construction activities to an estimated level.

An ongoing program of monitoring will support continued safe operation of the TSF including:

- Regular reconciliation of deposition against plan.

- Geotechnical investigations conducted prior to construction.

- Monitoring of TSF condition day-to-day.

- Design reviews with qualified tailings engineers as required. 


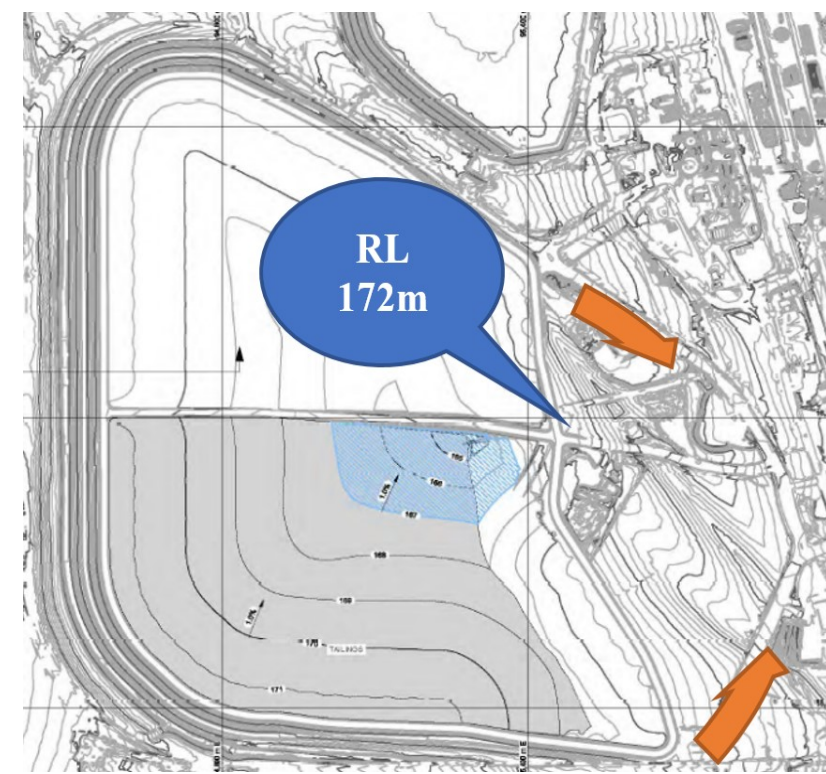

(a)

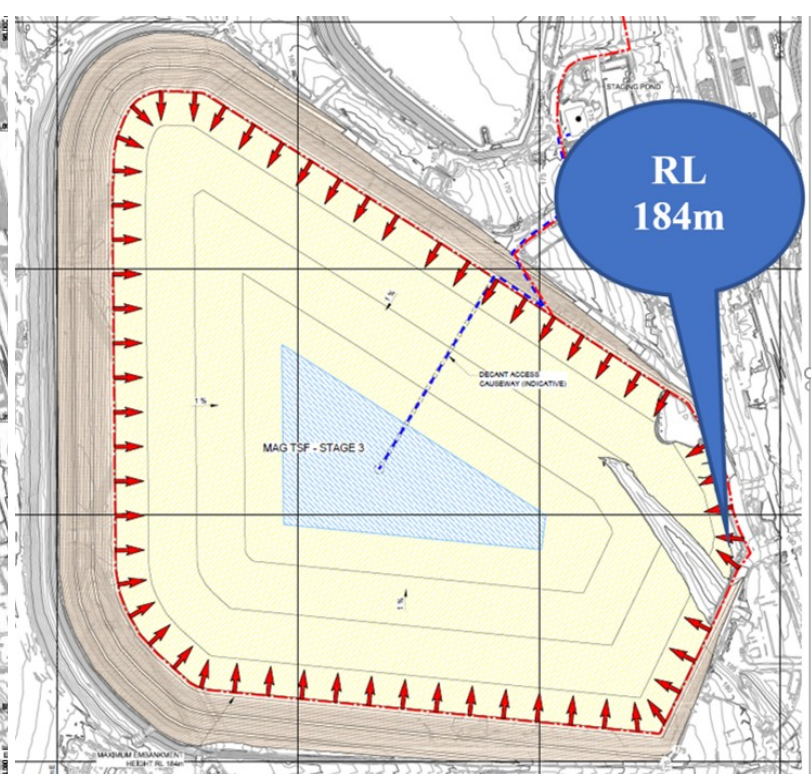

(b)

Figure 10 (a) End of first five-year plan; (b) End of second five-year plan

\section{Conclusion}

The following conclusions can be drawn following commissioning and conversion to PDCD configurations:

- The dewatering polymer allowed rapid water release and solids to drop out at the deposition point.

- The low turbidity and quality of released water allowed operations to return water back to the process and is proof that the ultra-fine particles settled close to the deposition points.

- A sufficient beach formed against the embankments and directed the released water away from the embankments towards the decants for recovery.

- Cycling of deposition points after thin layers of tailings deposition allowed for excellent dewatering, drying and consolidation to reach the required strength, density and moisture levels.

\section{Acknowledgement}

The successful conversion of the conventional Mag TSF to a perimeter discharge central decant configuration using Nalco WaterShed polymer was the result of a massive team effort.

Special thanks to Golder Associates for developing the master plan and deposition model and executing the civil design and test work, and to Nalco Water for the WaterShed polymer system design and support.

The following people (SIMEC Mining's Technology Development \& Major Capital Projects) deserve a special mention: Mike Bannear, Blair Owens, Morgan Lee-Dean, Luke Shimmin, Glenn Philips and Leendert Payne.

\section{References}

Golder Associates 2014, Geotechnical Testing and Analysis for the Future Raises of the Mag TSF Master Plan, report reference 147665005-030-R-RevO, dated 13 November 2014.

Golder Associates 2015a, Magnetite Tailings Storage Facility Operating Manual, report reference 147665005-051-R-Rev1, dated July 2015.

Golder Associates 2015b, Mag TSF Geotechnical Investigation, report reference 1539672-001-R-Rev0, dated October 2015.

Golder Associates 2017, Mag TSF Stability Assessment, report reference 1 772492-006-R-Rev0, dated 30 October 2017.

Verdoorn, F, Owens, B \& Gibbs, K 2018, 'Case study - SIMEC Mining Big Baron Pit successful tailings dewatering and management using WaterShed polymer', in RJ Jewell \& AB Fourie (eds), Proceedings of the 21st International Seminar on Paste and Thickened Tailings, Australian Centre for Geomechanics, Perth, pp. 305-320. 